\title{
Ultrastructure of the pollen grains of Withania somnifera (L.) Dunal (Solanaceae), A study from Saudi Arabia
}

\author{
Hussien M. Alwadie \\ Department of Biology, Faculty of Science, King Khalid University, \\ Saudi Arabia \\ E.mail: HussienAlwadie@hotmail.com.
}

\begin{abstract}
Alwadie, H. M. 2002. Ultrastructure of the pollen grains of Withania somnifera (L.) Dunal (Solanaceae), A study from Saudi Arabia. Taeckholmia 22(1):115-119.

Light microscopy, scanning and transmission electron microscopy were used to study the morphology and the ultrastructure of the pollen grains of Withania somnifera (L.) Dunal. Light microscopic examination revealed that the pollen grain is tri- or tetrazonocoplate, approximately as long as broad measuring $29-\mu \mathrm{m}$. Scanning electron microscopic observation showed that surface sculpture is scarbate-granulate. Ultrathin sections as examined by transmission electron microscope showed that the pollen contained numerous starch grains, liped drops, endoplasmic reticulum and vesicles of dicotysomes. Two layers of pollen wall were also distinguished; the outer wall (exine divided into ektexine and enexine as well as an inner layer (intine). The nutritive values of Withania pollen were discussed. The importance of studying the ultrastructure of pollen grains as a new tool in plant taxonomy was also discussed.
\end{abstract}

Key words: Pollen grains, Saudi Arabia, Ultrastructure, Withania.

\section{Introduction}

Withania somnifera (L.) Dunal is an important medicinal plant belonging to the family Solanaceae and is described under many common names such as Indian ginseng and Ashwagandha. It is widespread in many places in the world e.g. in India, Africa and the Mediterranean region (Mabberly, 1997) and Saudi Arabia (Migahid, 1978; Collenette, 1985; Doaigey, 1991 and Collenette, 1998). Many active substances were extracted from this plant. Alkaloids were used for calming; withanolides for their anti-tumor and sitoindosides for their anti-stress activity (Elsakka et al., 1989 and Bhattacharya et al., 2000).

Pollen characters have received attention in taxonomic and pollen morphology, but still very little is known about the ultrastructure and cytochemistry. The mature pollen grains contain nutrients for the growing pollen tube (Jensen et al., 1974; Cresti, et al., 1975). Pollen wall stratification and internal structure can hardly be studied by light microscopy (Zavada, 1990); therefore scanning and transmission electron microscopy become necessary in examining these characters. El-Ghazaly (1990) and Harley et al. (2000) reported on the morphology of pollen grains of many plant species.

Ultrastructural studies on pollen grains of higher plants may add new information about their taxonomy, particularly the pollen wall. So far, no previous ultrastructural studies of pollen grains of Withania somnifera (L.) Dunal have been reported in Saudi Arabia. The aim of this paper is to describe the ultrastructural features of the mature pollen grain of this plant. It is one of a series of studies about the types of nutritive materials, which are found in the pollen grains and also to throw the light on new criteria of plant taxonomy using the ultrastructure of pollens. 


\section{Material and methods}

Pollen grains of Withania somnifera (L.) Dunal were obtained from herbarium specimens deposited at the herbarium of King Khaled University, Abha (Saudi Arabia).

Light microscopy (LM): Pollen grains were placed in glacial acetic acid for three minutes, acetolysed according the method of Erdtman (1960) and then mounted in glycerin gel for investigation by light microscopy using a $\mathrm{CH}_{2}$ Olympus microscope.

Scanning electron microscopy (SEM): Acetolysed pollen grains were placed on aluminum stubs, freeze dried and then coated with gold (Moore and Webb, 1978). The stubs carrying the pollen grains were examined and photographed using a JEOL JSM-T200 SEM at $25 \mathrm{KV}$.

Transmission electron microscopy (TEM): $1 \mathrm{~mm}^{3}$ cubes of agar containing fresh pollen grains were fixed for 24 hours in $2.5 \%$ glutaraldehyde with $0.05 \mathrm{M}$ cacodylate buffer at $\mathrm{pH} 7.4$ and postfixed in $1 \% \mathrm{OsO}_{4}$ in the same buffer for 2 hours (Cresti et al., 1985). The cubes were then dehydrated in graded series of ethanol, and embedded in Spurr's resin (Spurr, 1969). Ultrathih sections were cut using a diamond knife on ultramicrotome, stained with uranyl acetate followed by lead citrate (Reynolds, 1963). The stained grids were examined and photographed with a JEOL JEM 100 B TEM.

\section{Results and Discussion.}

Pollen grains of Withania somnifera (L.) Dunal are always seen attached to the style hairs (Fig. 1). They are trizonocolpate with 3 pores (Fig. 2) or tetrazonocolpate with 4 pores (Fig. 3) approximately as long as broad, with a diameter of 28-30 $\mu \mathrm{m}$. SEM observation showed that surface sculpture is scarbate-granulate (Fig. 4). These observations are in agreement with the results obtained by Moore and Webb (1978) and Ayyad (1988) on their studies on pollen of Solanaceae.

Examination by TEM revealed that the pollen wall consists of two distinct layers. The outer layer (exine) which is composed mainly of sporopollenin (Moore and Webb, 1978) is divided into two layers, ektexine and endexine (Figs. 5\&6). The ektexine is fairly uniform, of which three layers were visible: tectum, collumellae and foot layer (Faegri, 1956). The inner layer (intine), formed of fibrillar materials, is thick and similar to an ordinary cell wall (Figs. 5\&6). By using the conventional staining method (uranyl acetate/lead citrate) in TEM, the exine appeared to be stained more intensely than the intine (Figs. 5\&6). These results give an indication that the exine is composed of materials different from those of intine. The type of pollen wall may vary from species to another (Weber et al., 1999).

Cytoplasm of the mature pollen was found to be non-vacuolated and containing plastids with several starch grains, lipid drops, endoplasmic reticulum, mitochondria and small vesicles probably belonging to the dictyosomes (Figs. 5\&6). This description confirmed the findings of Kozar (1974) and Ayyad and Baka (1993). An increase of lipid drops and vesicles of dictyosomes was observed during the initiation of pollen tubes (Ayyad and Baka, 1993). Fawcette (1966) suggested that these lipid drops serve as a reservoir of high-energy material 
and as a potential source of short-chain hydrocarbons for the synthesis of membranes and other lipid-bearing cellular components necessary for the construction of germ tube in the germinating pollen grain.
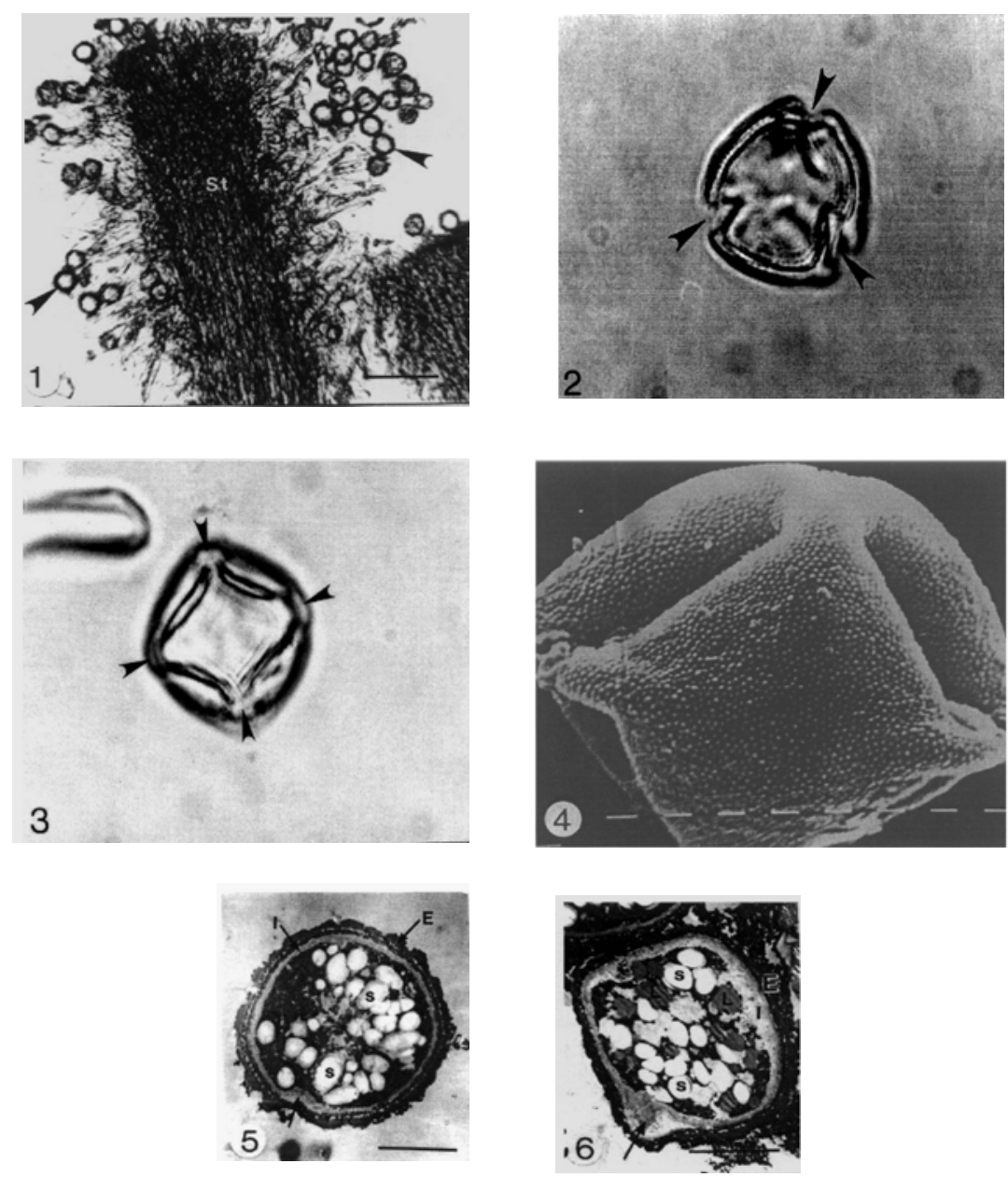

Figures 1-6. 1. Light micrograph of hairy style (St) of Withania somnifera showing many attached pollen grains (arrows). Bar $=50.0 \mu \mathrm{m}$. 2. Light micrograph showing a pollen grain of Withania somnifera with 3 pores. Bar $=1.0 \mu \mathrm{m}$. 3. Light micrograph showing other view of pollen grain of Withania somnifera with 4 pores. Bar $=1.0 \mu \mathrm{m}$. 4. SEM Withania somnifera pollen grain. Note the pores and the granulation of the surface. Bar $=5.0 \mu \mathrm{m}$. $\mathbf{5}$. Transmission electron micrograph of a cross section of Withania somnifera pollen showing exine (E), intine (I), and starch grains (S). Note the pore (arrow). Bar $=5.0 \mu \mathrm{m}$. 6 . Transmission electron micrograph of a cross section of Withania somnifera pollen grain showing starch grains (S), lipid drops (L), electron-dense exine (E), and electron-lucent intine. Not the initiation of pollen tube (arrow). Bar $=5.0 \mu \mathrm{m}$. 
Ayyad and Baka (1993) have used period acid-thiocarbohydrazide-silver proteinate technique (PATCLISP) to localize the polysaccharides in the pollen grains of Plantago major L. They reported that silver was deposited on endexine of exine, intine, starch grains, vesicles of dictyosomes and lipids indicating that these structures contain polysaccharides. Positive staining of lipids by PATCHSP method could explain the fact that these pollen contain lipid drops mixed with polysaccharides. The intine is mainly formed of cellulose as the normal plant cell wall (Moore and Webb, 1978) or of pecto-cellulose substance (Kozar, 1974). E1Ghazaly and Jensen (1987) reported that the exine of the mature pollen of Triticum aestivum was positively stained when PATCHSP method was used indicating that the nature of the material of exine in Triticum pollen is different from that in Plantago pollen. These differences may give a support for the use ultracytochemical methods as new tools in plant taxonomy. Further cytochemical studies are needed to study Withania pollen. More advanced techniques such as localization of enzymes and isoenzymes are needed to clarify this point. The present results indicate that Withania somnifera (L.) Dunal pollen contains different nutrients. It is well known that pollen grains are used as robust in Europe.

\section{References}

Ayyad, S.M. 1988. Pollen grain ecology of the Mediterranean Sea coast, Egypt. Unpublished PhD thesis, Faculty of Science, University of Al-Mansoura, Egypt. 220 pp.

-. \& Baka, Z. A. M. 1993. Ultrastructure and localization of polysaccharides in pollen grains and young pollen tubes of Plantago major L. J. of Environmental Sciences, Al-Mansoura University, Egypt 5:221-234.

Bhattacharya, S.K.; Bhattacharya, A.; Sairam, K.; \& Ghosal, S., 2000. Anxiolyticantidepressant activity of Withania somnifera glycowithanolides: an experimental study. Phytomedicine 6:463-469

CoIlenette, S. 1985. An illustrated guide to the flowers of Saudi Arabia. MEPA Flora Pub.1. Scorptiori Publ. Ltd., London.

1998. A checklist of botanical species in Saudi Arabia. International Asclepiad Society.

Cresti, M.; Pacini, E.; Sarfatti, G.; \& Simoncioli, C. 1975. Ultrastructural features and storage function of Lycopersicum peruvianum pollen. In: Mulcalty, D.L. (ed): Gamete Composition in Plants and Animals, 19-27, North -Ho land Publications Company, Amstrdam.

; Clampolini, F.; Mulcahy, D.L.; and Mulcahy, G. 1985. Ultrastructure of Nicotiana alata pollen, its germination and early tube formation. Amer. J. Bot. 72:719-727.

Doaigey, A.R. 1991. Occurrence, type, and location of calcium oxalate crystals in leaves and stems of 16 species of poisonous plants. Amer. J. Bot. 78:1608-1616.

El-Ghazaly, G. 1990. An illustrated key to endoaperture morphology. Review of Palaeobotany and Palynology 63:227-231.

\& Jensen, M. A. 1987. Development of wheat (Triticum aestivum) pollen. II. Histochemical differentiation of wall and ubisch bodies during development. Amer. J. Bot. 74:1396-1418.

Elsakka, M.; Pavelescu, M.; Grigorescu, E. 1989. Withania somnifera, a plant with great therapeutical future. Review of Medical and Chir. Society Med. Nat. Jasi., 
93: 349-350.

Erdtman, G. 1960. The acetolysis method revised description. Sven. Bot. Tidstr. 54:651-564.

Faegri, K. 1956. Recent trends in palynology. Bot. Rev. 22:639-664.

Fawcette, D.W. 1966. An atlas of fine structure. The cell, its organelles and inclusion. WB. Saunders Co., Philadelphia.

Harley, M.; Morton, C.; and Bl ickinore, S. 2000. Pollen and Spores, Morphology and Biology. Royal Botanic Garden, Kew, London.

Jensen, W.A.; Ashton, M.; and Ileckard, L. R. 1974. Ultrastructural studies of the pollen subtribe Castilleine, family Scrophulariaceae. Bot. Gaz. 135:210-218.

Kozar, F. 1974. Ultrastructure of pollen of Opuntia polycantha. Canadianj of Botanys 25:313-315.

Mabberly, D.J. 1997. The plant-book A dictionary of the vascular plants. $2^{\text {nd }}$ ed. Cambridge University Press.

Migahid, A.M. 1978. Flora of Saudi Arabia. $2^{\text {nd }}$ ed. Riyadh University Press.

Moore, P. D. \& Webb, J. A. 1978. An Illustrated Guide to Pollen Analysis. Hodder and Stroughton, London, Sydney, Aukiand, Toronto.

Reynolds, E. S. 1963. The use of lead citrate at high $\mathrm{pH}$ as an electron-opaque stain in electron microscopy. J. of Cell Biology 17:208-212.

Spurr, A. R. 1969. A low-viscosity epoxy resin embedding medium for electron microscopy. J. of Ultrastructural Research 26:31-43.

Weber, M.; Halbr, H. \& Hesse, M. 1999. The basic pollen wall types in Araceae. International J. of Plant Science 160: 415-423.

Zavada, M.S. 1990. A contribution to the study of pollen wall ultrastructure of orchid pollinia. Annales Mo. Botanical Garden. St. Louis 77:785-801. 